\title{
Looking Up and Looking Out: Career Mobility Effects of Demographic Similarity Among Professionals
}

\section{Citation}

McGinn, Kathleen L., and Katherine L. Milkman. "Looking Up and Looking Out: Career Mobility Effects of Demographic Similarity among Professionals." Harvard Business School Working Paper, No. 12-110, June 2012.

\section{Permanent link}

http://nrs.harvard.edu/urn-3:HUL.InstRepos:9056791

\section{Terms of Use}

This article was downloaded from Harvard University's DASH repository, and is made available under the terms and conditions applicable to Open Access Policy Articles, as set forth at http:// nrs.harvard.edu/urn-3:HUL.InstRepos:dash.current.terms-of-use\#OAP

\section{Share Your Story}

The Harvard community has made this article openly available. Please share how this access benefits you. Submit a story. 
H A R VARD D B S I N E S S S C H O O L

\section{Looking Up and Looking Out: \\ Career Mobility Effects of Demographic Similarity Among Professionals}

Kathleen L. McGinn

Katherine L. Milkman

\section{Working Paper}

$12-110$

June 13, 2012 


\section{Looking up and looking out:}

\section{Career mobility effects of demographic similarity among professionals ${ }^{1}$}

\author{
Kathleen L. McGinn \\ Harvard Business School \\ Harvard University \\ Boston, MA 02163 \\ $\mathrm{Ph}: 617-495-6901$ \\ kmcginn@hbs.edu
}

\author{
Katherine L. Milkman \\ Wharton School \\ University of Pennsylvania \\ Philadelphia, PA 19104 \\ $\mathrm{Ph}: 215-573-9646$ \\ kmilkman@wharton.upenn.edu
}

Draft accepted to Organization Science, May 2012

\footnotetext{
${ }^{1}$ We are grateful to Anne Mercogliano, Cailin Hammer and Julia Morgan Williams for their able assistance on multiple aspects of the research and to Harvard Business School for funding. We thank many generous colleagues and seminar participants at Cornell, Harvard, INSEAD, London Business School, MIT, NYU, and the University of Utah for their insightful feedback on this paper. This research was made possible by the employees of "KLM" who graciously shared their data, time, and stories with us.
} 


\begin{abstract}
We investigate the role of workgroup sex and race composition on the career mobility of professionals in "up-or-out" organizations. We develop a nuanced perspective on the potential career mobility effects of workgroup demography by integrating the social identification processes of cohesion, competition, and comparison. Using five years of personnel data from a large law firm, we examine the influence of demographic match with workgroup superiors and workgroup peers on attorneys' likelihood of turnover and promotion. Survival analyses reveal that higher proportions of same-sex and same-race superiors enhance junior professionals' career mobility. On the flip side, we observe mobility costs accruing to professionals in workgroups with higher proportions of samesex and same-race peers. Qualitative data offer insights into the social identification processes underlying demographic similarity effects on turnover and promotion in professional service organizations.
\end{abstract}

The race and gender composition of an organization's top ranking employees results from hiring, promotions and turnover within the firm. Women and racial minorities have increasingly crossed the threshold into organizations, but the path to the top remains elusive (Eagly and Carli 2007; Smith 2002). In spite of diversity in the demographics of those entering their organizations, new cadres of leaders look remarkably similar to the cadre preceding them (Fernandez and Fernandez-Mateo 2006). Mirroring their limited access to promotions, underrepresented groups exit firms at higher rates than their White, male counterparts (Hom et al. 2008), making way for the next cohort to repeat this pattern. Organizations and scholars continue to search for answers to help redress these inequalities.

We study career mobility in a single professional service organization. Professional service organizations, such as law firms, accounting and consulting firms, and universities, control or shape some of society's most vital resources and are thus a particularly important domain for examining issues of diversity. Inequalities by sex and race in the most senior ranks of professional service organizations remain rampant (Bertrand et al. 2009). The demographic characteristics of professionals working in law firms illustrate these inequalities. In 2009, women made up 46 percent of associates but just 19 percent of partners across U.S. law firms (Collins 2009). Racial minorities comprised 20 percent of the lawyers across all ranks in the U.S. in 2009 but only six percent of partners (Collins 2009). Inequities in representation by gender and race at the highest levels persist despite more equal proportions of women and minorities in "pipeline" law school programs and entry-level ranks for decades past. The persistent underrepresentation of women and minorities at the top of these firms appears to result from disproportionately low rates of promotion and high rates of turnover among women and minorities in spite of their increasing representation in the talent pool (Kay and Hagan 1998).

Scholars have long sought an understanding of the factors underlying the slow rate of change in race and gender composition at the top of organizations. Ideally, career mobility singularly reflects employee performance, but past research finds that employee and workplace demography shape 
supervisors' evaluations of performance and employees' career mobility in demonstrable ways (Castilla and Benard 2010; Hull and Nelson 2000). Studies of relational demography (Tsui and Gutek 1999) and workgroup composition (e.g., Elvira and Cohen 2001; Sørensen 2000) attribute career mobility patterns to a critical intersection between individual and organizational factors - the demographic match between an individual and other members of his or her organization. Payoffs from in-group social cohesion and costs from between-group competition have been cited as potential mechanisms underlying the influence of relational demography on career mobility (Jackson et al. 1991; O'Reilly et al. 1989; Zatzick et al. 2003). But research on workgroup composition and relational demography has produced contradictory findings and ignored how a separate product of social identification - social comparison-may conflict or work in concert with in-group cohesion and between-group competition. The presence of similar others may lead to social comparisons by decision makers and by employees themselves if ascriptive characteristics are perceived to be a salient category for evaluations and promotions (Duguid et al. 2010; Reagans 2005). Social comparisons may be especially influential in professional service organizations, where careers depend upon a challenging up-or-out promotion hurdle to the highest ranks. For professionals in such organizations, the benefits accruing to demographic similarity between subordinates and supervisorslooking up to others like one's self — may differ substantially from those accruing to similarity among peers - having to look out for others like one's self.

\section{WORKPLACE DEMOGRAPHY AND CAREER MOBILTIY IN PROFESSIONAL SERVICE ORGANIZATIONS}

Professional service organizations incorporate several human capital features that have implications for the study of workgroup demography and career mobility. First, a professional service organization's primary asset is its human capital — the knowledge, skills, and connections of its professionals (Sherer 1994; Von Nordenflycht 2010). This makes voluntary turnover of skilled professionals extremely costly for the organization. Second, the human resource structure is pyramidical. Up-or-out promotion policies (Kahn and Huberman 1988) drive professionals to "prove" their value to the organization over a fairly well-specified time period early in their careers (Sherer 1994) and lead to grueling work hours and limited time for social interaction not necessitated by work itself (Hewlett and Luce 2006). Third, a group of senior professionals decides which junior professionals move up and which move out. These practices politicize promotions (Gandz and Murray 1980), making senior sponsorship vital for selling a given junior professional to those making promotion decisions. Finally, the socialization process in many professional service organizations is intense and critical to career mobility (Anderson-Gough et al. 2000), leading to pressure to "fit in." Taken together, the human capital features of professional service organizations have the potential to heighten the value of demographic similarity between junior and 
senior professionals on juniors' career mobility, while simultaneously diminishing the value of demographic similarity among junior peers.

\section{Demographic match and promotions}

Countering arguments that performance alone drives promotions, performance evaluations have been shown to be affected by the demographic match between supervisors and subordinates (Castilla 2011; Tsui and O'Reilly 1989). More direct support for homophily effects in promotions comes from a study of women's careers within California savings and loan associations: promotions were curvilinearly related to higher proportions of female superiors, with increasingly positive effects up to a threshold (Cohen et al. 1998). In a professional service setting, analyses of promotions across a nationwide sample of U.S. law firms revealed higher proportions of male partners within a firm were negatively associated with the odds that the firm would promote women into the partnership ranks (Gorman 2006). Across a broader, representative sample of employed workers in three U.S. cities, White men, Black men and women, and Latino men reporting to ascriptively similar managers were twice as likely to have been promoted in the preceding year as those reporting to ascriptively dissimilar managers, but these effects did not hold for White women and Latinas (Elliott and Smith 2004). After controlling for relative opportunity, however, all groups exhibited essentially identical levels of homosocial reproduction: "In other words, ingroup favoritism may be universal, but opportunities to practice it are not" (Elliott and Smith 2004: 381).

In contrast to the consistent, if sparse, findings on the promotion benefits of working with demographically-similar superiors, the implications of working with same-race or same-sex peers are more equivocal. A representative sample of U.S. workers revealed a negative association between the proportions of Black employees in the organization and promotion rates for Blacks, but no parallel association for Whites (Baldi and McBrier 1997). The overrepresentation of Whites in managerial positions may help explain why negative career outcomes accrue to Blacks but not Whites in the presence of higher proportions of same-race peers. Turning to demographic match by sex, higher proportions of same sex workers in an occupation were associated with lower chances of attaining a managerial position over time in a representative sample of U.S. workers (Maume 1999). In contrast, a study limiting its exploration to majority-female jobs in the savings and loan industry found positive peer effects: the odds of women's promotions rose with higher proportions of women at and below their own level in an organization (Cohen et al. 1998). Overall, this research provides mixed evidence regarding the promotion effects of working alongside same-race or same-sex peers.

\section{Demographic match and turnover}

The limited empirical studies measuring the effects of race or sex similarity on turnover offer few conclusive results. Three available studies, all carried out in majority-female workgroups or business units, found that higher same-race representation within workgroups decreased the likelihood of racial 
minorities' voluntary exit (Leonard and Levine 2006; Sørensen 2004; Zatzick et al. 2003). The effects for working with same-sex coworkers were more mixed. In a study of U.S. business units with female majorities, higher proportions of female coworkers at and above an employee's job level generally decreased the likelihood of women's voluntary exit, but there was no parallel effect on men's exits (Elvira and Cohen 2001). In contrast, a study carried out in a different, large U.S. organization employing majority women found higher proportions of female coworkers generally increased the likelihood of women's exit, while higher proportions of male coworkers decreased the likelihood of men's exit (Leonard and Levine 2006). The commonalities in populations across all of the studies of peer race and gender effects on turnover-low skill level, majority-female jobs in majority-female workplacessuggest that the generalizability of the findings to professional service organizations may be limited.

Tolbert et al. (1995) studied the turnover effects of workplace demography among professionals in high skill level jobs in a majority-male work setting, as traditionally observed in professional service organizations. They examined the effects of the proportions of male and female faculty in 50 academic sociology departments in a given year on the likelihood that at least one male or female professor would exit the department during the subsequent year. Increases in the overall proportions of women faculty in a department increased the likelihood that at least one woman would leave the department, but this effect decreased as women achieved approximately 40 percent representation. The effects appeared to vary with women's status in the department: higher overall proportions of women faculty increased the likelihood of a woman's exit, but higher proportions of women among the tenured faculty decreased the likelihood of a woman's exit. Male faculty exits were generally unrelated to males' representation in the department. Reconciling past research on demographic match and career mobility

The differences in study design and results across past research linking workplace demography to career mobility suggest four general conclusions. First, the influence of demographic match on career mobility depends on the organizational levels occupied by demographically similar employees in the workplace. Supervisor-subordinate demographic match appears to have consistently positive effects on subordinates' career mobility, while demographic similarity among peers has markedly inconsistent effects on mobility. Second, career mobility within organizations involves turnover and promotion, but the effects on turnover may not precisely track the effects on promotion. Third, the effects of demographic match for members of traditionally high status groups - men and Whites — are likely to differ from those for members of traditionally lower status groups - women and racial minorities. Finally, career mobility effects vary across the traditionally lower status groups - outcomes for racial minorities may not mirror those for women. Our research builds from this starting point; by simultaneously considering the turnover and promotion effects of race and gender match within and across levels in the organization, we are able to develop a comprehensive set of hypotheses regarding the relationship between workplace demography and career mobility in professional service organizations. 


\section{SOCIAL IDENTIFICATION PROCESSES UNDERLYING}

\section{EFFECTS OF DEMOGRAPHIC MATCH ON CAREER MOBILITY}

Establishing and maintaining a positive social identity, "that part of an individual's self-concept which derives from his knowledge of his membership in a social group (or groups) together with the emotional significance attached to that membership" (Tajfel 1974: 69), is fundamental to an individual's selfesteem. Social categorization, the tendency to view others as similar or dissimilar to the self along identity dimensions, relates an individual's social identity to his or her perceptions of others (Tajfel and Turner 1986). Taken together, social identity and social categorization act as a "system of orientation which creates and defines the individual's own place in society" (Tajfel 1974).

Race and sex are notably salient identity and categorization dimensions (Cota and Dion 1986; Frable 1997; Porter and Washington 1993). Social identification and categorization by race and gender draw organizational members from the same demographic groups together (Hogg and Terry 2000; Lincoln and Miller 1979), heighten perceptions of similarity and attraction (Byrne 1971), generate competition between groups (Tajfel and Turner 1986; Duguid et al. 2010), and heighten individuals' awareness of those categories when selecting referents for social comparisons (Brewer and Weber 1994; Kruglanski and Mayseless 1990). Through these processes of cohesion, competition and comparison, race- and gender-match with superiors and coworkers may have marked effects on career mobility. Within-group cohesion and between-group competition as drivers of career mobility

Substantial evidence suggests that within-group social cohesion paves the way for cooperative, supportive relationships between supervisors and their demographically similar subordinates (Roberson et al. 2007; Tsui et al. 2002). Given the opportunity, decision makers tend to exhibit in-group preferences in terms of hiring, evaluating, sponsoring and promoting employees (Barker et al. 1999; Kanter 1977a; Ragins and McFarlin 1990). In-group cohesion also promotes communication and supportive relationships among workgroup peers (Chattopadhyay et al. 2008; Riordan and Shore 1997; South et al. 1982b), leading to social ties that increase attachment to the workgroup and discourage exit (Ibarra 1992; Popielarz and McPherson 1995). In the absence of pressure to compete for promotion, having similar others around tends to enhance positive career mobility, regardless of where the similar others sit in the hierarchy (Elvira and Cohen 2001; Zatzick et al. 2003).

Majority groups have long benefited from the positive association between strong numerical representation and career outcomes (Kanter 1977b), but lack of power may limit the payoffs to greater minority group representation (Bobo and Hutchings 1996; Ibarra 1992, 1995; Mehra et al. 1998). Differences across demographic groups in the benefits accruing to in-group social cohesion and the costs associated with between-group competition offer a potential explanation for the inconsistent connection between representation and turnover in past research. Women and racial minorities may face increasing 
resistance from White men as their historical dominance in the workplace is threatened (Blalock 1967; South et al. 1982a). In professional service organizations, where junior employees implicitly or explicitly compete for up-or-out promotions, distrust and dislike of dissimilar others may spur between-group competition for limited positions in the organization, leading powerful groups to drive out members of potentially threatening minority groups (Tolbert et al. 1995).

Social comparisons as drivers of career mobility

Studies linking relational demography to career mobility have focused on within-group cohesion and between-group competition as theoretical explanations for their findings, but these explanations may be insufficient for fully understanding the effects of demographic match on career mobility in professional service organizations. A separate social identification process - social comparison - may provide additional insight and predictive power in environments where there is significant competition for promotions. Tajfel and Turner's (1986) conception of the social comparison process involves an evaluation of one's identity vis-à-vis membership in one group differentiated from another group (e.g., a woman compared to a man), while Festinger's (1954) conception focuses on social comparisons of one's attributes relative to the attributes of others within one's in-group (e.g., a woman compared to other women). Whether across or within groups, the choice of referent other in social comparisons is often based on demographic characteristics of the self and other (Belliveau 2005; Kilduff et al. 2010; Major et al. 1984).

The pertinent question professionals ask when making social comparisons with their superiors is: “Can people like me succeed here?" This form of similarity testing invokes between-group comparisons (Mussweiler 2003), providing employees with data on how people from their identity group are valued relative to those from other identity groups. A female professional might, for example, compare promotions given to women with those given to men when considering the opportunities for women's advancement (Roth 2003). Social comparisons involving demographically-similar superiors are likely to invoke positive reflection on the self (Brewer and Weber 1994); demographic match with superiors signals to a subordinate that his or her own success is attainable (Barker et al. 1999; Scandura 1992). Such signals can fuel sustained effort as professionals work their way toward promotion, while simultaneously and positively affecting decision makers' views of who is suitable for promotion.

The pertinent question professionals ask when making social comparisons with their peers is: "Can I succeed here?" This question invokes dissimilarity testing and within-group comparisons, weighing one's own opportunities relative to those of others from one's own demographic group (Brewer and Weber 1994). A female professional may, for example, compare her own pay and promotion opportunities with those of other women doing similar work in the organization (Major and Forcey 1985). Demographically similar junior professionals are structurally equivalent actors competing for support from the same senior professionals (Krackhardt and Porter 1986). As decision makers face a growing pool 
of structurally equivalent subordinates, comparisons within demographic groups may affect their promotion and termination decisions (Duguid et al. 2010). To the extent that workers believe decision makers engage in within-group comparisons, it behooves the employees to assess their chances of success relative to demographically similar referents. In such a context, social comparisons among demographically-similar peers evolve into an increasingly negative competition as the number of similar employees rises (Reagans 2005). As the pool of relevant others grows, the likelihood of potential competitors increases, reducing cooperation among group members, dampening an individual's chance of promotion, and potentially prompting exit.

Integrating effects of cohesion, competition and comparisons on career mobility

By integrating understandings of social cohesion, competition and comparison, all of which may be triggered by demographic match within workgroups, it is possible to develop a more nuanced perspective on the potential career mobility effects of workgroup demography within professional service organizations. Across hierarchical levels, the identity processes work in concert to drive a predicted positive association between greater proportions of demographically-similar supervisors and a professional's upward career mobility. First, payoffs from within-group social cohesion should be positive. Second, between-group competition should decrease as representation of an individual's demographic group in the leadership ranks grows, at least for those with sufficient power in the organization. Finally, because demographically similar others serve as social referents, an increase in the proportion of demographically similar others at higher levels in one's workgroup should also enhance upward career mobility. Formally, we hypothesize:

HYPOTHESIS 1 (H1): The higher the proportion of within-workgroup senior professionals of the same sex or same race as a junior professional, the lower the likelihood of the junior's exit and the higher the likelihood of the junior's promotion.

For professionals from historically underrepresented and low power demographic groups, reduced payoffs from cohesion and increased competition from members of traditionally powerful demographic groups may hamper minorities' career mobility as their group's representation in the leadership ranks rises, minimizing the payoffs from increasing proportions of minorities in senior positions. Social comparison arguments, in contrast, suggest that the historical dearth of women and underrepresented minorities in leadership positions is likely to amplify minority members' reliance on numerical evidence indicating whether "people like me" can succeed within their workgroups. Increasing proportions of demographically similar senior professionals would offer a more meaningful social comparison to women and minorities than to white males, who have no need to look up narrowly within their own workgroups to assess the chances that members of their demographic group can succeed in their organizations. Considering cohesion, competition and comparison effects simultaneously leads to the prediction that payoffs from greater proportions of demographically similar superiors will vary among 
White males, women, and underrepresented racial minorities, but leaves the direction of moderation by demographic group in dispute. Reflecting the general conclusions from past research, we predict:

HYPOTHESIS 2 (H2): A junior professional's race and sex will moderate the effects of proportions of within-workgroup senior professionals of the same sex or same race as the junior professional on the likelihood of that junior's exit and promotion.

Our review of the literature suggests that the career mobility effects associated with higher proportions of demographically similar workgroup peers will differ from the effects associated with higher proportions of demographically similar superiors. Social cohesion among similar peers may enhance junior professionals' attachment to the organization while exerting limited impact on decision makers' promotion and termination decisions. Instead, organizational leaders may, intentionally or unintentionally, compare or choose among members from the same demographic group when selecting which junior professionals to mentor and sponsor. Even implicit demographic quotas in promotions may lead to perceived associations between increasing numbers of similar others and decreasing chances of any one individual's success. Social comparisons within demographic groups may lead junior professionals in up-or-out organizations to view their chance of success less positively when there are higher proportions of demographically similar peers in their workgroup — being the best among few is more likely than being the best among many. Specifically:

HYPOTHESIS 3 (H3): The higher the proportion of within-workgroup junior professionals of the same sex or same race as a junior, the higher the likelihood of the junior's exit and the lower the likelihood of the junior's promotion.

For women and underrepresented minorities, the downside of increasing demographic representation among peers may be amplified. In-group social cohesion conveys benefits for majority group members with access to resources and information (Berger et al. 1978; Brass 1984), but interaction among women and underrepresented minorities may lead to structural marginalization, creating "ghettoes" of low-power minority groups (Mehra et al. 1998) facing hostility from the higher-power majority group (Bobo and Hutchings 1996). As a result, women and underrepresented minorities may distance themselves from others in their own identity group (Duguid et al. 2010), heightening negative social comparisons with similar others. We therefore predict that the harmful effects of higher proportions of demographically similar peers will be greater for women and underrepresented minorities than for those in the demographic majority. Specifically:

HYPOTHESIS 4 (H4): A junior professional's race and sex will moderate the effects of proportions of within-workgroup peers of the same sex or same race as the junior professional on the likelihood of that junior's exit and promotion, exaggerating the effects for women and underrepresented minorities relative to members of the relevant majority demographic group. 


\section{THE ORGANIZATIONAL SETTING AND DATA}

We study the effects of workgroup demographics at a large international law firm, which we call KLM. ${ }^{2}$ KLM was a well-established firm recognized by The American Lawyer as one of the top 20 "A-List" law firms in the U.S. over multiple years during the five-year study period. Examining turnover in one organization with clearly demarcated workgroups and a strict junior-senior hierarchy allows us to disentangle the effects of workgroup sex and race composition within and across hierarchical levels on junior professionals' career mobility. We restricted our analyses to attorneys in KLM's U.S. offices in light of substantial differences in demographics, employment law, and work practices across countries.

To familiarize ourselves with KLM's organizational structure, norms, informal interactions, work practices, and promotion procedures, we initially spent several days observing meetings and events in the firm's two largest offices. We talked informally with junior and senior attorneys and Human Resource staff and formally interviewed six associates (4 women; 2 men) and three partners ( 2 women; 1 man), asking general questions to enrich our understanding of how attorneys in the firm worked and interacted with one another and more focused questions about the factors that could affect their chances of promotion or lead them to consider leaving the firm. The formal interviews lasted one to three hours. Two of the firm's Human Resource staff provided us with written copies of firm policies and other firm documents and answered our inquiries throughout the study.

KLM employed an average of 589 lawyers in its U.S. offices during the five-year period of our study. Twenty-eight percent of KLM's U.S. based attorneys worked in a single location, and the rest were spread across ten smaller locations. Within each location, professionals practiced in small workgroups defined by areas of expertise and led by a subset of partners. For example, all of the lawyers in the patents and trademarks practice group in the New York office comprised one workgroup. Interviews revealed that most of an attorney's interactions with coworkers occurred within his or her local workgroup. We therefore measured demographic match at the workgroup level for all of our analyses. Workgroups, which averaged 4.5 senior and 6.1 junior attorneys, experienced turnover each year due to hiring and attrition, but attorneys typically stayed in one workgroup throughout their tenure in the firm.

Juniors entered the organization immediately after completing degrees at highly regarded law schools or laterally from other firms. The attorneys' experiences prior to law school varied—some had never held a job before; others had pursued careers in different sectors. Professionals entered the firm

\footnotetext{
${ }^{2}$ The first author was invited into KLM by a senior woman in the organization, with the support of the organization's leadership group. The purpose was to assess the extent to which the organization had reached its goal of gender equality. In lieu of compensation, KLM provided personnel data and access to the organization's current employees. The authors agreed that all findings would be shared with KLM. In turn, the organization consented, in writing, to allow the data to be used in published research without review by KLM.
} 
already well-educated, at roughly the same age (late 20's to early 30's), and earned high salaries. Starting salaries in the last year of our study averaged \$160,000. In short, the juniors at KLM varied by gender, ethnicity and some life experiences, but relative to the general population they were notably similar to one another.

Promotions to partnership could occur at different points for different employees, but they were clustered in years six through nine of a junior's career. Because of the mix in hires between "laterals" (previously employed as an attorney) and "rookies" (hired directly from law school), promotions could and did occur as early as the first year an attorney was employed in the firm. Attorneys elected when to apply for promotion, with guidance from partners within their workgroup. A comment made by one of KLM's junior attorneys during an interview highlighted how up-or-out promotion practices affected the lives of attorneys throughout their junior years:

One of the challenges in a place like this is that there really is one opportunity for advancementthat is partnership. There is a lot you need to do to put yourself in a position where that is a possibility. You need to do that a lot earlier than you would in a situation where the immediate opportunities for advancement are a little more regular.

Promotion decisions were announced at the beginning of each calendar year. A small group of senior leaders from across the firm made the promotion decisions with input from partners personally familiar with the relevant junior's work. Workgroup seniors were thus critical to junior attorneys' promotions. Most decisions were final, but a few associates were given an opportunity to reapply. If a junior was not promoted and was not given an opportunity to reapply, he or she had to exit the firm. There were very few exceptions to this rule-less than two percent of lawyers had not yet received a promotion or exited KLM by their tenth year in the firm. ${ }^{3}$

Data

Quantitative data. KLM provided personnel records for all professionals employed by the organization at any point during the five years beginning in January 2002 and ending in December 2006. Each employee's record documented his or her self-declared sex, racial category (possible categories were Caucasian, Asian or Pacific Islander, Black, Hispanic, Native American, other ethnicity, and undeclared), marital status, and birth date, as well as the employee's office location, practice area (e.g., litigation), start date (and thus, tenure), rank in the organization, date of promotion to partner (if applicable), departure date (if applicable), and nature of departure (voluntary or involuntary, if applicable). Departures were recorded as involuntary if the attorney was formally terminated; all other departures were recorded as voluntary. We consider the distinction between voluntary and involuntary departures in the results section. An important limitation of the data obtained from KLM is that it does not

\footnotetext{
${ }^{3}$ Maintaining a limited number of "non-track" professionals is standard practice in law firms, most commonly in "of counsel" positions.
} 
include information on employee performance. Performance is tightly linked with professionals' career mobility and the absence of this data limits our ability to separate mobility outcomes from performance.

Prior to releasing their personnel data, KLM deleted all employee names and assigned unique identification numbers to each employee record and associated exit interview. The personnel data set provided by KLM included observations of 631 unique individuals at the junior level. To ensure that our analyses were as unbiased as possible, we dropped a number of problematic observations before running our regressions. First, we eliminated all observations involving juniors who remained at the organization for over twelve years without receiving a promotion $(\mathrm{N}=5)$. These professionals had passed the point at which they could plausibly receive a promotion and thus no longer fit our definition of junior professionals. Next, we dropped all observations of juniors not assigned to a workgroup $(\mathrm{N}=98)$. These employees were usually employed for a limited period of time, primarily as summer interns. We also dropped all observations of juniors who worked in office locations with fewer than 15 employees $(\mathrm{N}=$ 16) or practice areas with fewer than 5 employees $(\mathrm{N}=1)$. Dropping observations from these small workgroups allowed us to include controls for each junior's location and practice area without over-fitting our data. After eliminating these observations, our final sample included 511 juniors distributed across seven locations, 13 practice areas, and 60 workgroups.

Qualitative data. In addition to the qualitative data we collected through observation and interviews of current employees, KLM supplied copies of archived notes from all exit interviews conducted during the study period. Firm Human Resource (HR) representatives conducted the interviews during an attorney's final days of employment as part of a broader exit process mandated by the firm. Approximately 70 percent of the junior attorneys who voluntarily left the firm were interviewed by HR staff at the time of exit; this dropped to ten percent for those who were terminated. HR representatives used a standard form to guide the questions asked about departing employees' experiences at KLM, reasons for leaving, and expected future employment, but interview practices varied and the data provided by the firm suggest that not all questions on the form were asked in all interviews. It is also important to note that employees may not have been entirely forthcoming about their experiences and beliefs during these exit interviews in light of impression management and future career concerns.

Two research assistants, blind to the topic of study, coded the exit interviews for reasons for exit and relationships with peers and senior attorneys. The inter-coder agreement rate across all codes was 89 percent. One author acted as arbiter for all disagreements. Since the firm conducted and supplied exit interviews for only a subset of the attorneys leaving KLM and there are no parallel interviews with attorneys who stayed, we analyzed data from exit interviews primarily to gain insights into our quantitative results. 


\section{VARIABLES AND ANALYSES}

Departures $(\mathrm{N}=243)$ were far more common than promotions $(\mathrm{N}=38)$, requiring different approaches to the quantitative analyses of these different events. We first describe the variables and analyses used to test the effects of workgroup demography on departure events and then turn to promotion events.

\section{Analyses of departures}

We modeled an employee's departure hazard using discrete time survival analysis, which relies on logistic regressions to analyze the likelihood that a given employee will exit the organization within a discrete period of time (Morita et al. 1993; Singer and Willett 1993). Survival analysis provides unbiased coefficient estimates for data sets that include censored events (e.g., when a junior is promoted). Discrete time survival analysis assumes that events take place at regular intervals rather than randomly across time. This assumption is consistent with our data, in which exits were associated with annual hiring and review cycles at the firm. The majority of juniors entered KLM at the same time each year; promotion decisions were announced once at the beginning of each calendar year; and terminations following unsuccessful applications for promotion similarly took place in a cluster early each year. Terminations and voluntary exits not linked to promotions occurred at less regular intervals but reflected the annual hiring and promotion cycle within the legal profession. These annual events affected the composition of workgroups as well as the likelihood that juniors would exit KLM. Because of this annual periodicity in the events of interest for our study, we set the discrete time interval in our analyses to one year.

The data set used in our survival analyses included one observation per junior attorney for each year that the junior was employed at the firm between 2002 and 2006. This resulted in 1,437 personperiod observations of the 511 unique junior attorneys at KLM. Our primary analyses examine the effects of the proportions of demographically similar others at the supervisor and peer levels on whether or not a junior exited the organization either voluntarily or involuntarily, treating promotions during a given period as censored data.

Predictor variables. Following Cohen, Broschak and Haveman (1998) and Tolbert et al. (1995), our measures of demographic similarity reflect the proportion of others in the same demographic category as the focal junior. To measure a junior's similarity with workgroup seniors, we calculated the proportion of seniors in a junior's workgroup who were the same sex as the junior (Sex \% Match - Sr) and the percentage of seniors who were of the same, specific racial category as the focal junior-Caucasian, Asian or Pacific Islander, Black, Hispanic, or other ethnicity (Race \% Match-Sr). We created parallel measures of demographic similarity at the peer level, capturing the proportion of other juniors in the workgroup who were the same sex as the focal junior (Sex \% Match-Jr) and the proportion of juniors within the workgroup who were the same race as the focal junior (Race \% Match - Jr). 
Since the percentages of same sex or same race coworkers are difficult to interpret for extremely small groups, we calculated them only when there were at least two seniors or two other juniors in a junior's workgroup. To account for workgroups with only one or two seniors, we created a dummy variable indicating whether there were fewer than two seniors in the workgroup and set the senior match variables to zero for such workgroups. We did the same for the junior match variables when the workgroup included fewer than two juniors other than the lawyer in question.

To test whether demographic similarity with others differentially affected members of underrepresented demographic groups, we standardized our match variables and created interaction terms. We interacted each standardized sex match variable with a dummy variable indicating whether an employee was female (female $=1$; male $=-1$ ) (Aiken et al. 1991). ${ }^{4}$ This created one interaction term for senior sex match (Female $x$ Sex \% Match - Sr) and another for junior sex match (Female $x$ Sex \% Match$J r)$.

Creating the parallel interaction term for race match required that we determine which racial minority groups were underrepresented. We used the U.S. federal Equal Employment Opportunity (EEO) standards to define underrepresentation. EEO standards compare a racial group's representation in the population with the same group's representation in the organization. Blacks and Hispanics each comprised roughly 12 percent of the U.S. population in 2002 and less than six percent of the professionals in KLM at the time. Native Americans made up approximately one percent of the U.S. population and just 0.5 percent of KLM professionals. Asians counted for less than four percent of the general population and 9.6 percent of the professionals at KLM. The representation of racial minorities at KLM roughly mirrored the representation of these groups among legal professionals across the U.S. (American Lawyer 2010). Thus, we coded Blacks, Hispanics, and Native Americans, but not Asians, as underrepresented minorities. ${ }^{5}$ We also include "other ethnicity" observations in the underrepresented category. We interacted the standardized junior race match variable (Race \% Match - Jr) with a dummy variable indicating whether the junior belonged to an underrepresented racial group (Black, Hispanic, Native American, or other ethnicity $=1$; Asian or Caucasian $=-1$ ). Because there were so few underrepresented minorities in the senior ranks $(<2 \%$; see Table 1$)$, we did not create an interaction term for our senior race match variable.

Control variables. Individual demographic controls included dummy variables indicating the junior professional's sex (female $=1$; male $=-1$ ), underrepresented racial status (Black, Hispanic, Native

\footnotetext{
${ }^{4}$ Effect coding (coding dummy variables $+1 /-1$ ) has two advantages: 1 ) the regression intercept is the overall mean (averages across all the levels of the other variable), rather than the mean of one of the groups, and the coefficients on the effect coded variables correspond to the difference between one group and the overall mean, rather than the difference between one group and another group; and 2) interaction terms are considerably less correlated with the effect coded variables.

${ }^{5}$ None of the exit variables differed significantly between Caucasians and Asians (all p > .20; see Table 2). Promotions were marginally less likely for Asians than Caucasians $(p<.10)$, so we treat them as separate groups in our promotion analyses.
} 
American or other $=1$; Asian or Caucasian $=-1)$, undeclared race $($ undeclared $=1$; declared $=0)$, and a continuous variable denoting the junior's age. We controlled for each employee's tenure with a set of dummies indicating the junior's years of tenure at the firm (omitted dummy $=9+$ years). We also included a dummy variable controlling for whether or not the junior was working part-time (part time $=1$; full time $=0$ ). We included a number of additional controls related to the work environment. At the workgroup level, we controlled for juniors' potential access to seniors with a variable indicating the ratio of seniors to juniors in the junior's workgroup (\# Seniors in gp/\# Juniors in gp). We also added dummy variables controlling for the junior's practice area (e.g., litigation) and the junior's office location (e.g., New York). Four dummy variables controlled for the calendar year in question (year 1 omitted).

Model of turnover. We used the following logistic regression specification to model turnover:

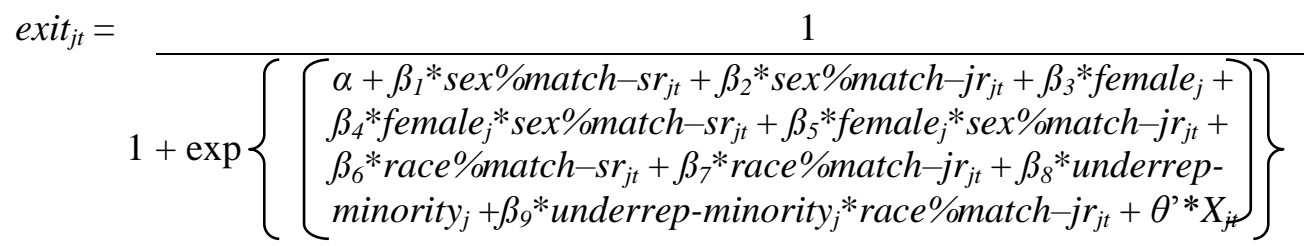

where $e^{x i t} t_{j t}=1$ when junior employee $j$ exited the organization in period $t$ and zero otherwise. Match variables varied by time period $t$. For example, race\%match-sr $r_{j t}$ equals the proportion of senior employees in the workgroup of junior employee $j$ during time period $t$ who share $j$ 's declared racial category. $X_{j t}$ was a vector of the control variables described above.

\section{Analyses of promotions}

Promotions occurred much less frequently than departures, so we took a different approach to modeling these rare events. We first collapsed our person-period data set to produce one observation per employee. For time-varying predictors (e.g., \% of same-race juniors in an employee's workgroup) we calculated the average over each junior's tenure at KLM. This resulted in a static data set of all promotion events across five years. We then dropped all observations in workgroups averaging two or fewer seniors or fewer than two other juniors over the five years. Using this static data set, we applied King's rare events logit model (King and Zeng 2001) to analyze the impact of demographic similarity with workgroup seniors and peers on a junior attorney's chance of promotion. King's model corrects for small samples and rare events when estimating coefficients (King and Zeng 2001). ${ }^{6}$

Thirty-eight attorneys were promoted over the five years studied, but five were in workgroups with too few seniors or juniors to allow analyses of demographic match. Of the remaining 33 attorneys promoted during our study period, 31 were Caucasian (22 males and 9 females) and 2 were Asian (both male). We therefore restricted our promotion analyses to Caucasians and Asians ( $N=396 ; 331$

\footnotetext{
${ }^{6}$ Although highly unstable to specification changes, survival models produce very similar findings.
} 
Caucasians and 65 Asians) and included a dummy variable indicating race (Asian $=1$; Caucasian $=0$ ).

This allows us to test the effects of race and sex match on promotions but does not allow for any examination of underrepresented minorities (none of whom were promoted).

The primary predictor variables in the promotion analyses were the averages of each of our standard group match variables (e.g., Avg Sex \% Match - Sr) over the period during our study that a junior attorney was employed at KLM. The averages excluded any year in which an employee worked in a group with fewer than two seniors or two other juniors, consistent with the approach taken in our exit analyses.

Controls for sex, racial status, and part-time employment in the promotion analyses are the same as those used in the exit analyses. Controls for age and tenure at the firm were calculated at the average over the data collection period. At the workgroup level, to control for a junior's overall access to senior attorneys, we averaged the ratio of seniors to juniors in the junior's workgroup across the years in our data set (Avg. (\# Seniors in gp/\# Juniors in gp)). We also included dummy variables controlling for the junior's office location.

\section{RESULTS}

Among the 511 junior attorneys and across the five years studied, 170 junior attorneys voluntarily exited the firm, 73 were terminated, and 38 were promoted to partner. The remaining 230 were still employed as junior attorneys at the firm at the end of our study period. Table 1 presents a summary of organizational and individual characteristics in our sample during an average year. Table 2 presents the frequency of turnover and promotion events by sex and race categories over the five-year period studied. Table 3 describes the distributions of the match variables in our data set for first year juniors (i.e., juniors in their first year of employment with KLM, regardless of the calendar year in which their first year of employment took place).

Insert Tables $1,2 \& 3$ about here

\section{Departures}

In the KLM data set, voluntary exits are more frequent in the early years of employment while terminations increase later in junior professionals' tenure. This observation does not offer any insights into whether voluntary departures and terminations are separate or linked events, i.e., whether attorneys voluntarily exit in anticipation of possible termination later. The exit interviews offer a glimpse into the array of reasons junior attorneys chose to leave KLM. We coded the stated reasons for exit into five inductively derived categories: better opportunities; life balance; leaving law or the workforce; discontent with the firm; and limited opportunities at the firm. Over a third of the responses (37\%) fell into the first category, suggesting voluntary departures often occurred for "pull" reasons that may have had little to do with feeling "pushed" out of the firm. The comments coded into "life balance" and "leaving law or the 
workforce," are ambiguous and do not allow us to draw conclusions about whether the exits were fully voluntary. But over a quarter of the responses (28\%) fell into "discontent with the firm" or "limited opportunities at the firm," suggesting many exiting attorneys were leaving because they believed their chances for success within the firm were low, i.e., in lieu of anticipated termination at a later date. One record of an exit interview stated, for example, "Believes $100 \%$ that she would never make partner." Others were less direct but conveyed similar sentiments, e.g., "Lack of career opportunities;" "things didn't look good here;" and "[no] long term fit." In light of the qualitative evidence suggesting that a non-negligible portion of voluntarily exiting attorneys linked their departure with the possibility of future termination, we treat the two types of exits as one event type in our primary analyses. In secondary analyses, we examine voluntary exits and terminations separately.

All exits. Table 4 presents means, standard deviations, and correlations for the variables in our departure analyses. Table 5 displays the results of discrete time hazard analyses of all junior departures, grouping voluntary exits and terminations together as exit events. Model 1 is a baseline model including only our control variables. Model 2 adds the main effect predictor variables. Model 3 adds the interaction terms that allow us to test our hypotheses and overarching model of career mobility. Likelihood ratio tests shown in Table 5 confirm that Model 3 provides a significantly better fit than the controls only model and the main effect model, but the main-effect only model does not provide a significantly better fit than the controls only model.

\section{Insert Tables 4 \& 5 about here}

In Model 1, we observe a pattern of significant coefficients on all but one of the tenure dummies, indicating that juniors with increasingly longer tenure exhibit a higher hazard of exit. Juniors who did not declare a racial category (Race Unknown) were significantly more likely to exit than Caucasians or Asians. ${ }^{8}$

Because Model 2 provides no better fit than Model 1, we turn next to the results from Model 3. The coefficients on the tenure dummies and undeclared racial category (Race Unknown) remained significant with the addition of workgroup demographic variables. In addition, the main effect for underrepresented minority status was significantly related to turnover in the full model: the estimated odds of an underrepresented minority exiting in any given year were 41.3 times that of an Asian or Caucasian when relative workgroup composition was held constant. The ratio of senior to junior attorneys

\footnotetext{
${ }^{7}$ The omitted variable for tenure is the dummy variable for 9 or more years of tenure. The coefficient for the dummy variable for 8 years of tenure is not significant $(\mathrm{p}>.10)$, indicating that the likelihood of exit does not differ between junior attorneys with 8 and 9 or more years of tenure.

${ }^{8}$ Omitting the nine observations for junior attorneys who did not declare a specific racial category does not materially affect the pattern of results or the significance levels of any of our predictor variables.
} 
in a workgroup also reached significance in Model 3: a 25 percentage point increase in the ratio of seniors to juniors in the workgroup decreased the fitted odds of a junior's exit by a factor of 2.6.

Turning to our predicted effects, we first consider the effects of demographic match with senior attorneys and then turn to the effects of demographic match with junior attorneys. The hazard of exit fell significantly with higher proportions of same-sex seniors in the workgroup but was not affected by the proportion of same-race seniors. These findings provide support for $\mathrm{Hl}$ in terms of gender match but not race match.

The coefficient on the interaction term for same-sex seniors was significant, consistent with $H 2$. The negative coefficient indicates that working with same sex seniors had stronger effects on women than on men. For women, a ten percent increase in the percentage of senior women in the workgroup multiplies the fitted odds of exit by a factor of 0.79 , indicating a 21 percent decrease in the odds of exit associated with a ten percent increase in the percentage of senior women in the workgroup. The percentage of senior men in the workgroup has no effect on junior males' odds of exit. Figure 1(a) illustrates the fitted probability of survival as a function of a junior female employee's years at the firm in workgroups with the minimum (0\%) and maximum (67\%) observed proportions of same-sex (female) seniors. The probability of still remaining in the firm after five years was roughly 0.75 for junior women in workgroups where 67 percent of the partners were female; this falls to roughly 0.25 for junior women in workgroups with no female partners.

Turning to demographic match with peers, an increase in the proportion of same sex peers in a junior's workgroup had a significant, positive effect on the likelihood of a junior's exit, offering support for $H 3$. This effect was not significantly moderated by the gender of the junior attorney-both male and female attorneys were more likely to leave when they worked with higher proportions of same-sex peers. On average, a one standard deviation increase in the percentage of same sex peers in a junior's workgroup (a 26 percentage point change) multiplies the fitted odds of exit by 1.4 for males and 1.2 for females; in other words, junior men experience a 40 percent increase in the odds of exit and junior women experience a 20 percent increase in the odds of exit when the representation of same-sex peers in the workgroup increases by 26 percent. Figure 1 illustrates the fitted probability of survival for females (1b) and males (1c) as a function of a junior employee's years at the firm in workgroups with the minimum $(0 \%)$ and maximum (100\%) observed proportions of same-sex juniors.

\section{Insert Figure 1 about here}

Race similarity among peers also significantly influenced a junior's likelihood of exit, providing additional support for $H 3$. The coefficient on the interaction with underrepresented minority status is positive and significant, consistent with $H 4$. An ten percent increase in the percentage of same race peers in a junior's workgroup multiplies the fitted odds of exit by a factor of 1.5 , indicating a 50 percent increase in the odds of exit associated with a ten percent increase in same race peers. Figure 1(d) 
illustrates the fitted probability of survival as a function of a junior underrepresented minority employee's years at the firm in workgroups with the minimum (0\%) and maximum $(40 \%)$ observed proportions of same-race underrepresented minority juniors. For Caucasian and Asian employees, there is no meaningful effect. The findings presented in Model 3 are robust to numerous alternative specifications. ${ }^{9}$

\section{Analyses by type of exit event. We turn next to analyses modeling voluntary and involuntary} turnover separately. Model 4 (see Table 5) presents the results of discrete time hazard analyses of the effects of our predictor variables on voluntary exit events, treating terminations and promotions during a given period as censored data. A likelihood ratio test showed that Model 4 improved significantly upon a control-only model $\left(\operatorname{LR} \chi^{2}(7)=21.01, \mathrm{p}<.005\right)$. The pattern of results is similar in direction and magnitude to the pattern of results in our combined exit data, with the exceptions of a non-significant main effect for proportion of same sex seniors and a marginally significant main effect for the proportion of same race seniors in the regression on voluntary exit. Although the effect for proportion of same race seniors did not reach standard significance levels, it is important to note that the sign of the coefficient is opposite our prediction - higher proportions of same race seniors within a junior's workgroup were associated with a higher likelihood of the junior attorney's voluntary exit.

Model 5 (see Table 5) presents an analysis of the causes of involuntary exits, treating voluntary exits and promotions during a given period as censored data. A likelihood ratio test indicated that our demographic match predictor variables did not significantly improve the goodness-of-fit over the simpler controls-only model $\left(\operatorname{LR} \chi^{2}(7)=7.89, \mathrm{p}>.10\right)$. One interpretation is that the patterns we observe in Model 3 were driven by voluntary exit events primarily and not by termination events. Alternatively, the small number of termination events in our data set may limit our power to the point that we cannot assess the relationship between workgroup characteristics and terminations. The coefficients on demographic match variables in Model 5 were directionally similar to those in Model 3, but only one was statistically significant in the termination model (Sex \% Match - Sr). We can test the empirical similarity between terminations and voluntary departures by comparing coefficient estimates across Models 4 and 5; in this test, none of our predictor coefficients differ significantly across the models. ${ }^{10}$ We therefore maintain it is unreasonable to draw any strong conclusions about whether the effects of workgroup demography on terminations were distinct from the effects on voluntary exits.

\footnotetext{
${ }^{9}$ Running the model separately for males and females yielded the same pattern of results as that presented in Model 3. Substituting fixed effects for a junior's law school graduation date instead of firm tenure does not change our results. Clustering standard errors by workgroup and calendar year does not change our results. We observe the same pattern of results in multinomial logit models with three levels including no change in status, voluntary turnover, and termination. Details of these analyses are available from the authors.

${ }^{10}$ Across the forty-six predictors included in our survival model, the beta coefficient estimates for six control predictors differ significantly between Models 4 and 5: three tenure dummies (years 0, 2 and 3), age, Race Unknown, and one office location dummy.
} 
Alternative model specifications suggested by past research. Past research has identified inflexion points for the effects of women's representation on women's career mobility (Kanter 1977b; Tolbert et al. 1995), so we conducted supplementary analyses to test for nonlinearities in our data. Examining the raw data by percentile match scores revealed no evidence of curvilinear relationships at the senior or peer level, for race or sex match. Adding quadratic terms to Model 3 for the four workgroup demography variables did not significantly increase our predictive power $\left(\operatorname{LR} \chi^{2}(4)=2.32, p>.50\right)$, and none of the coefficients on the quadratic terms were significant.

Studies of team diversity find that overall levels of diversity within a team significantly influence individual and team outcomes (Harrison and Klein 2007; Williams and O'Reilly 1998). To test the effect of overall workgroup diversity relative to proportions of same-sex or same-race seniors and peers, we created two workgroup-level measures of diversity and examined their fit with our data. Neither measures of race and gender diversity nor measures of age and tenure diversity were significant predictors of exit in our data. ${ }^{11}$

\section{Promotions}

Table 6 presents the results of King's rare events logit regressions predicting the promotion of a White or Asian junior at any point during the five-year period included in our data. Model 6 is a baseline model including only our control variables. In the control-only model, an increase in the average proportion of seniors relative to juniors in a junior's workgroup significantly increased the likelihood of a junior's promotion. Model 7 adds our main effect workgroup demographic variables. Model 8 includes the interaction terms.

The rare events logit regression does not generate a log-likelihood ratio and, therefore, does not allow a test of the change in log-likelihood across models. In light of this constraint, we estimated the relative goodness of fit across the models using standard logistic regression models run with the variables presented in Table 6 . The standard regressions result in similar significance levels for the variables of interest. Likelihood-ratio $\chi^{2}$ tests from the standard models found that the main effects and interactions model (estimating Model 8) was a better fit than the main effect only model $\left(\operatorname{LR} \chi^{2}(2)=7.69, \mathrm{p}<.05\right)$ and the controls only model $\left(\operatorname{LR} \chi^{2}(6)=14.00, \mathrm{P}<.05\right)$. Consistent with the departure analyses, the main effect only model did not improve the fit over the controls only model $\left(\operatorname{LR} \chi^{2}(4)=6.31, p>.10\right)$.

We see in Model 8 that neither of the main effects at the senior level (Avg Race \% Match - Sr; Avg Race \% Match - Sr) was significantly associated with promotion. However, the significant, positive

\footnotetext{
${ }^{11}$ Adding four Blau (1977) workgroup-level race and gender diversity measures - the standardized Blau index measuring workgroup race diversity; the interaction term between the Blau race diversity index and underrepresented minority status; the standardized Blau index measuring workgroup gender diversity; and the interaction term between the Blau gender diversity index and being female - did not increase the goodness of fit over Model 3. The inclusion of mean Euclidean distance measures at the workgroup level for tenure and age (Harrison and Klein 2007) again added no predictive power over Model 3. Further, none of these diversity measures were significant predictors of exit. Details of these analyses are available from the authors.
} 
interaction between the proportion of same sex seniors and our female dummy variable (female $=1$; male $=-1$ ) indicates that higher proportions of senior women within the workgroup were associated with a higher likelihood of promotion for junior women. The parallel does not hold for junior men. This provides support for $\mathrm{H} 2$ but does not support the main effect hypothesis, $\mathrm{H} 1$.

At the peer level, higher proportions of same-race peers in the workgroup (Avg Race \% Match$J r$ ) significantly reduced the chance of promotion for Caucasian and Asian juniors. The coefficient for the proportion of workgroup peers who are the same sex as the focal employee (Avg Sex \% Match-Jr) is not significant. The marginally significant, negative interaction between this peer-level match and gender (female $=1$; male $=-1$ ) suggests that higher proportions of same-sex peers within a workgroup may reduce the likelihood of promotion for junior women, while increasing the likelihood for junior men. Summary of quantitative findings

The quantitative data show that the relationship between workgroup demography and the career mobility of junior professionals varies with the race and gender of the focal employee and the hierarchical level at which demographic matches occur. Higher proportions of female seniors in a junior woman's workgroup decreased the likelihood of the junior woman's exit from the firm and increased her likelihood of promotion. Higher proportions of female peers, however, increased the likelihood that a junior woman would exit and marginally decreased the likelihood of promotion. A different pattern held for junior men. Higher proportions of male seniors had no effect on junior men's mobility. At the peer level, higher proportions of male peers increased the likelihood that junior men would exit while, paradoxically, marginally increasing their chances for promotion.

Proportions of same race seniors had no effect on junior attorneys' career mobility in the organization we studied. It is important to note that because so few underrepresented minorities worked in groups with seniors of their own race, the mechanisms we hypothesized would drive turnover effects cannot truly be tested with our data. At the peer level, however, underrepresented minorities — but not Caucasians or Asians - were more likely to exit the firm when they worked with higher proportions of other junior attorneys of the same race. Caucasians and Asians experienced the negative effects of working with higher proportions of same race peers at promotion time: the likelihood of a Caucasian or Asian being promoted was negatively associated with higher proportions of same race peers in the workgroup. Promotion effects could not be assessed for underrepresented minorities, since not a single junior Black, Hispanic or Native American attorney was promoted during the period of our study.

\section{Qualitative analyses}

The quantitative results establish a pattern of effects, but they do not allow an exploration of why the relationships between workgroup demographics and career mobility exist. Our qualitative data help illuminate the mechanisms underlying theses effects. 
Senior effects. Why does the proportion of female partners in a junior woman's workgroup affect that junior woman's likelihood of exit and promotion? In-person interviews conveyed juniors' heavy reliance on senior sponsors. Within-workgroup seniors supplied valued support, feedback and assignments to juniors, and juniors acknowledged a need for senior support in the promotion process. Illustrating this point, a junior female interviewee talked about an early, strategic decision she made to affiliate with a specific group of senior colleagues "because it is an important part of the ... review process here. You need to be recommended by [the seniors in] your group ... so the sooner you are able to start fostering connections within that group, the better."

But why did the effects for working with same-sex partners hold for women and not for men? Exit interviews provided evidence that juniors' perceptions of the amount and quality of support they received from senior attorneys varied by gender. Roughly equal proportions of men and women providing exit interviews mentioned mentors, sponsors, or alliances with senior professionals (26 and 23 percent of men and women, respectively), but the men were much more likely to report satisfaction with the relationships. Seventy-one percent of the males who mentioned senior mentors or sponsors spoke of these relationships positively while only 29 percent of the women mentioning seniors spoke positively of the relationships. Although junior men and women reported similar access to senior partners, the relatively rare opportunities to work with female partners meant that the positive effects of within-group social cohesion across ranks were more exceptional for women than they were for men.

Interviews with female attorneys who remained at the firm illuminated the role female partners played in attracting women to the firm and affecting their desire to remain; in contrast, none of the men we interviewed commented on partners' gender. A junior female talked about the scarcity of senior women in her workgroup: "We have in this office one [senior] woman right now ... it is not so much that I need a female mentor, I have found wonderful male mentors, but more that you worry about a signal." One female attorney who had been promoted to partner recently explained:

One of the things that was appealing to me about coming here is that there are actually successful women substantially more senior to me who have...very successful careers and involved lives with their children. That to a large extent sets [KLM] apart.

The qualitative data suggest that the presence of female partners within workgroups was especially salient for junior women. Women sought relevant, within-workgroup social comparisons to assess the chances of success for "someone like me," and appeared to be making career decisions based, in part, on this assessment. Although the quantitative data limit our ability to assess how the presence of within-workgroup minority partners may have influenced the career mobility of juniors from underrepresented racial groups, comments offered in exit interviews suggest the dearth of minority partners and the "nonexistent real mentoring for associates" influenced underrepresented minorities' career assessments in ways parallel to those expressed by junior women. 
Peer effects. Why does the proportion of same-sex or same-race peers in a junior professional's workgroup affect that professional's likelihood of exit and promotion? Consistent with the quantitative findings, the qualitative data suggest that partners compared across junior attorneys and junior attorneys compared themselves to their peers. A Caucasian male attorney we interviewed commented:

Some of the partners have been a little better recently about explaining ... what will make you stand out among your peers and sort of shine ... There are times when I don't get my weekends and I'll work an 80 hour week back to back to back. But ... you just have to be willing to step it up for short periods of time, for that sprint. The willingness to do that will make you stand out. Similarly, a Latina associate noted that partners: "will present things to you I suppose if they are behind you, you know, they then want to give you the opportunities to make yourself more visible in the firm." Within-group social comparisons were a source of uneasiness for some of the attorneys. A Caucasian female expressed discomfort with the possibility that she was being treated better than other junior women:

I am finding out now that not everybody gets the same welcome reaction when they are pregnant or when they want to start working part-time or something like that. But I have ... and now I'm heading out again [to have another child] and I expect the same thing will happen when I come back, that there will still be, you know, doors open to me.

The qualitative data hint at insufficient social cohesion among junior peers to offset the pressures of competitive social comparisons. Despite being physically proximate to one another, the juniors we interviewed said they spent the majority of each day engaged in independent work. In an illustrative response from an exit interview, a male junior commented that: "interactions were fine but sometimes rare, as the job can be isolating."

For junior women, an increase in the likelihood of exit in response to higher proportions of female peers reasonably accompanies the parallel decrease the likelihood of promotion. But why would junior men, the dominant and powerful group in the firm, exit at higher rates from workgroups with higher proportions of male peers, especially when the higher presence of male peers may increase their likelihood of promotion? Exit interviews suggest men voluntarily left the firm when they perceived that the partners were favoring other associates. A Caucasian male voiced frustration in his exit interview about the: "inequities in distribution of work, blatant differences in associates' treatment, [failure to involve him in]... deals that [he] expected to be on." Another exiting Caucasian male admonished the firm to "try to avoid sending negative messages because some are not asked to work on better cases, interesting cases." None of the exiting women or underrepresented minorities, however, made any comment about not getting choice assignments. Overall, the tenor of the social comparisons expressed in exit interviews differed by gender and race, in keeping with the differences in career mobility outcomes associated with the presence of demographically similar seniors and peers in the workgroup.

\section{DISCUSSION}


In the up-or-out organization we studied, higher proportions of same-sex superiors within a workgroup decreased women's likelihood of exiting the organization and increased their likelihood of promotion. In contrast, higher proportions of same-sex or same-race peers increased the likelihood of women's and men's exit and generally decreased their chances of promotion. These effects were moderated by race and gender. Positive outcomes for demographic match at the subordinate-supervisor level are consistent with past research. Our findings at the peer level add a crucial dimension to research on workgroup demography and career mobility.

Within-group social cohesion and social comparisons work in concert to make subordinatesupervisor demographic match beneficial to employees. Reflecting social cohesion within subordinatesupervisor relationships, the junior attorneys in our study turned to demographically similar seniors in their workgroups for support and sponsorship. Reflecting positive upward social comparisons across hierarchical levels, junior professionals identified demographically similar seniors as role models and looked to their representation in the senior ranks of their workgroup to predict whether people like themselves could succeed in the firm. Among peers, however, the potentially positive role for social cohesion was compromised by minimal interaction in day-to-day work, while limited opportunities for choice assignments and promotion lent a distinctly competitive edge to the work environment. Junior professionals perceived that they were "fungible goods," easily replaced by peers. Critically, our results show that these comparisons lead to measurable effects on individuals' careers, in turn shaping the demographic composition at the top of professional service organizations.

Past research finds that workplace demography affects members of traditionally high status groups - men and Whites - differently that it does those from traditionally lower status groups—women and racial minorities. Our research offers insights into why this is so. In the firm we studied, both men and women expressed a need for senior sponsorship, but the presence of females in leadership positions offered a vital signal in addition to their sponsorship. Higher proportions of same-sex seniors were more important for women than for men because the presence of female partners in the workgroup provided information to junior women that they could succeed, while junior men took the possibility of success for granted.

The dearth of underrepresented minorities in U.S. law firms and the low rate of promotion for underrepresented minorities relative to Caucasian and Asian lawyers is well documented (American Lawyer 2010). While not out of line with other firms, the scarcity of underrepresented minorities in the partnership ranks at the organization we studied restricted our ability to assess the impact of senior-junior racial match on the likelihood of juniors from underrepresented groups exiting the organization. And with no promotions over five years, there was no way to assess the impact of senior-junior racial match on the likelihood of promotion for underrepresented minorities. A recent study of hiring and promotions of Black lawyers within U.S. law firms offers evidence that the low promotion rates among Blacks result 
from the assignment of Black associates to less advantageous job tasks even after controlling for human capital observables such as law school quality, law school grades, and law review participation (Lehmann 2011). Our findings regarding the positive effects of women partners on women's promotions suggest that having higher proportions of underrepresented minority partners might ultimately lead to better task assignments for associates from underrepresented groups, but discriminatory assignments create a barrier to any potential for progress.

We examined the effects of workgroup demography in one professional service organization where human capital is critical to the organization's success, senior sponsorship is coveted by junior professionals, and competition for promotion is intense. The generalizability of our results may be limited to professionals in similar organizations. Past research (Baron et al. 2001) found that changing an organization's dominant employment model affects employee turnover. Future research should explore the hypothesis that responses to workplace sex and race composition vary with the cooperative and competitive dynamics in an organization: as necessary resources for success in competitive work environments become increasingly scarce, demographically similar peers may engage in fewer cooperative interactions and competition among them may increase, with consequences for career outcomes. Another critical limitation of our study is that our data did not include information on employee performance. Career mobility is linked with performance, and future research should explore the impact of the workgroup demographic variables studied here on employee performance and on career mobility controlling for performance.

Combining our findings regarding the career dampening effects of working with demographically similar peers with past research showing women and underrepresented minorities are more likely to be hired and promoted into jobs in which there are already higher proportions of similar others (Cohen et al. 1998; Elliott and Smith 2004) presents a conundrum for organizations. Are more women and members of racial minority groups coming into organizations only to be driven out by lack of sponsors, limited opportunities for social cohesion, and competitive social comparisons? If so, this could explain the continued underrepresentation of these groups in senior organizational positions in spite of increases in representation at junior levels. Our study has important implications for professional service organizations attempting to resolve this conundrum. We highlight the importance of considering both cooperative and competitive effects of demographic similarity for those interested in addressing the problem of persistent underrepresentation of women and minorities at the highest levels in organizations. Our findings suggest that clustering same race or same sex junior employees to provide an increased sense of community may have the opposite effect of that desired unless accompanied by senior professionals' active sponsorship of juniors across demographic lines. Furthermore, our results call for organizations to attend to the ways in which policies and practices invoke competition and comparison within demographic categories. Attempts to design employment practices that are blind to the demographics of candidates are likely to 
succeed only if all candidates perceive and receive equal mentoring, sponsorship, and peer support regardless of their race and gender. 


\section{Tables and Figures}

Table 1. Average demographic characteristics of the senior and junior employees (excluding those juniors dropped from survival analyses) at KLM during during the five years in our human resources data set.

\begin{tabular}{lcc}
\hline \hline & \multicolumn{2}{c}{ Yearly Average Over 6 Years } \\
\cline { 2 - 3 } Number in Organization & Senior Employees & Junior Employees \\
\cline { 2 - 3 } Number per Location* & 255 & 287 \\
Number per Department* & 36 & 49 \\
Number per Work Group* & 20 & 26 \\
Age & 4.5 & 6.1 \\
Tenure (Years Since Joining Firm) & 46 & 34 \\
\% Male & 9.6 & 2.4 \\
\% Caucasian & $79 \%$ & $56 \%$ \\
\% Asian & $93 \%$ & $76 \%$ \\
\% Black & $4 \%$ & $14 \%$ \\
\% Hispanic & $1 \%$ & $3 \%$ \\
\% Other Ethnicity & $1 \%$ & $4 \%$ \\
\% Ethnicity Unknown & $0 \%$ & $0 \%$ \\
\% Part Time & $1 \%$ & $2 \%$ \\
Number of New Hires & $3 \%$ & $8 \%$ \\
Number of Voluntary Departures & 15 & 63 \\
Number of Terminations & 3 & 34 \\
Number of Promotions & 6 & 15 \\
\hline \hline
\end{tabular}

* Group size statistics include juniors dropped from survival analyses.

Table 2. Proportions of Junior Attorneys who experience turnover and promotion events, by race and gender categories and type of career mobility event

\begin{tabular}{lccccc}
\hline \hline \multirow{2}{*}{ All Junior Attorneys } & $\mathbf{N}$ & \% Who Exit & \% Who Exit Voluntarily & \% Who Are Terminated & \% Who Are Promoted \\
\cline { 2 - 6 } & 511 & $48 \%$ & $33 \%$ & $14 \%$ & $7 \%$ \\
\hline Male & 277 & $47 \%$ & $35 \%$ & $12 \%^{\mathrm{a}}$ & $10 \%^{\mathrm{a}}$ \\
Female & 234 & $48 \%$ & $31 \%$ & $18 \%^{\mathrm{c}}$ & $4 \%^{\mathrm{b}}$ \\
\hline Caucasian & 390 & $46 \%$ & $32 \%$ & $13 \%^{\mathrm{a}}$ & $9 \%^{\mathrm{a}}$ \\
Asian & 73 & $45 \%$ & $37 \%$ & $8 \%^{\mathrm{a}}$ & $3 \%^{\mathrm{c}}$ \\
Underrepresented Minorities & 39 & $59 \%$ & $33 \%$ & $26 \%^{\mathrm{b}}$ & $0 \%^{\mathrm{b}}$ \\
\hline \hline
\end{tabular}

a significantly different from ${ }^{\mathrm{b}}$ at $\mathrm{p}<.05 ;{ }^{\mathrm{a}}$ marginally different from ${ }^{\mathrm{c}}$ at $\mathrm{p}<.10$

Note: 9 jrs did not declare a racial category 
Table 3. Summary statistics describing match variables in our person-period data set for first year junior employees. ${ }^{1}$

\begin{tabular}{|c|c|c|}
\hline & \multicolumn{2}{|c|}{ \% of Seniors in Group Who Share Race of Juniors Who Are: } \\
\hline & Caucasian or Asian & Underrepresented Minorities \\
\hline Average & $78 \%$ & $0 \%$ \\
\hline Std. Dev. & $35 \%$ & $2 \%$ \\
\hline \multirow[t]{3}{*}{$\mathbf{N}$} & 251 & 26 \\
\hline & \multicolumn{2}{|c|}{ \% of Peers in Group Who Share Race of Juniors Who Are: } \\
\hline & Caucasian or Asian & Underrepresented Minorities \\
\hline Average & $66 \%$ & $7 \%$ \\
\hline Std. Dev. & $28 \%$ & $11 \%$ \\
\hline \multirow[t]{3}{*}{$\mathbf{N}$} & 249 & 29 \\
\hline & \multicolumn{2}{|c|}{ \% of Seniors in Group of the Same Sex as Juniors Who Are: } \\
\hline & Male & Female \\
\hline Average & $80 \%$ & $21 \%$ \\
\hline Std. Dev. & $16 \%$ & $19 \%$ \\
\hline \multirow[t]{3}{*}{$\mathbf{N}$} & 152 & 125 \\
\hline & \multicolumn{2}{|c|}{ \% of Peers in Group of the Same Sex as Juniors Who Are: } \\
\hline & Male & Female \\
\hline Average & $59 \%$ & $45 \%$ \\
\hline Std. Dev. & $20 \%$ & $25 \%$ \\
\hline $\mathbf{N}$ & 147 & 131 \\
\hline
\end{tabular}

${ }^{1}$ Groups with fewer than two senior employees or three junior employees are excluded from these summary statistics. 
Table 4. Means and standard deviations (before continuous variables were normalized and before dummy variables were transformed to a $-1 / 1$ scale) and correlations of all transformed variables in person-period data set $(\mathrm{N}=1,437)$

\begin{tabular}{|c|c|c|c|c|c|c|c|c|c|c|c|c|c|c|c|c|c|}
\hline & $\sum_{\Sigma}^{\Xi}$ & 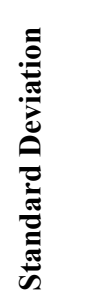 & 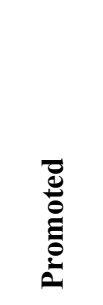 & 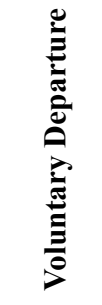 & 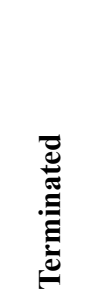 & 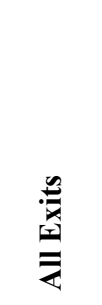 & 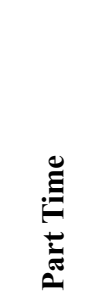 & $\underset{\&}{8}$ & 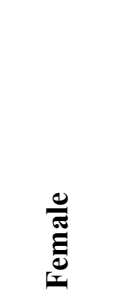 & 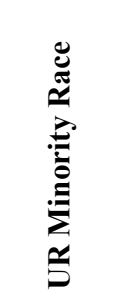 & 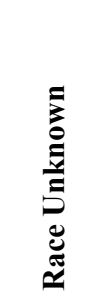 & 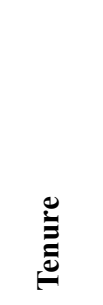 & 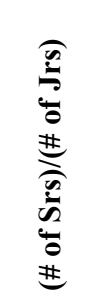 & 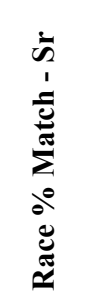 & 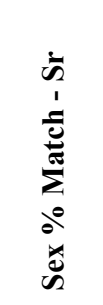 & 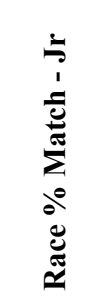 & 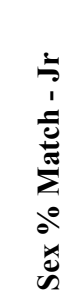 \\
\hline Promoted & 0.03 & 0.17 & 1.00 & & & & & & & & & & & & & & \\
\hline Voluntary Departure & 0.12 & 0.32 & $-0.07 *$ & 1.00 & & & & & & & & & & & & & \\
\hline Terminated & 0.05 & 0.22 & $-0.07 *$ & $-0.18^{*}$ & 1.00 & & & & & & & & & & & & \\
\hline All Exits & 0.17 & 0.38 & $-0.07 *$ & $0.81^{*}$ & $0.12^{*}$ & 1.00 & & & & & & & & & & & \\
\hline Part Time & 0.08 & 0.27 & -0.04 & 0.02 & 0.02 & 0.02 & 1.00 & & & & & & & & & & \\
\hline Age & 34.1 & 5.93 & $0.07^{*}$ & 0.00 & $0.20^{*}$ & $0.07 *$ & $0.12 *$ & 1.00 & & & & & & & & & \\
\hline Female & 0.44 & 0.50 & $-0.07 *$ & -0.01 & $0.08^{*}$ & 0.02 & $0.21 *$ & $-0.07 *$ & 1.00 & & & & & & & & \\
\hline UR Minority Race & 0.08 & 0.27 & -0.04 & 0.00 & $0.10^{*}$ & 0.03 & $0.10^{*}$ & -0.01 & $0.07^{*}$ & 1.00 & & & & & & & \\
\hline Race Unknown & 0.02 & 0.13 & -0.02 & 0.02 & $0.13^{*}$ & $0.07 *$ & 0.00 & $-0.07 *$ & 0.01 & -0.04 & 1.00 & & & & & & \\
\hline Tenure & 2.40 & 2.13 & $0.10^{*}$ & $0.05^{*}$ & $0.19^{*}$ & $0.15^{*}$ & 0.08 & $0.41^{*}$ & -0.03 & -0.05 & $-0.06 *$ & 1.00 & & & & & \\
\hline (\# of Srs)/(\# of Jrs) & 0.65 & 0.33 & $0.08^{*}$ & $-0.08 *$ & $0.06^{*}$ & $-0.07 *$ & 0.02 & 0.04 & 0.01 & -0.02 & -0.02 & 0.03 & 1.00 & & & & \\
\hline Race \% Match - Sr & 0.62 & 0.43 & $0.11^{*}$ & -0.03 & $-0.06^{*}$ & -0.05 & $-0.10^{*}$ & 0.04 & -0.05 & $-0.42 *$ & $-0.19^{*}$ & 0.04 & $0.28^{*}$ & 1.00 & & & \\
\hline Sex \% Match - Sr & 0.48 & 0.36 & $0.11 *$ & -0.01 & $-0.08 *$ & -0.05 & $-0.14 *$ & 0.00 & $-0.66^{*}$ & $-0.08^{*}$ & -0.04 & $0.06^{*}$ & $0.26^{*}$ & $0.30^{*}$ & 1.00 & & \\
\hline Race \% Match - Jr & 0.55 & 0.35 & 0.02 & -0.02 & -0.02 & -0.03 & -0.05 & 0.05 & -0.02 & $-0.40^{*}$ & $-0.20^{*}$ & $0.06^{*}$ & $-0.12^{*}$ & $0.67 *$ & $0.12^{*}$ & 1.00 & \\
\hline Sex \% Match - Jr & 0.47 & 0.26 & 0.02 & 0.05 & -0.04 & 0.02 & 0.01 & $0.10^{*}$ & $-0.13^{*}$ & 0.05 & -0.05 & -0.01 & $-0.14 *$ & 0.05 & $0.21 *$ & $0.33^{*}$ & 1.00 \\
\hline
\end{tabular}

*p-value $<.05$ 
Table 5. Junior employees are tracked using discrete time survival analysis to examine how the within workgroup demographic similarities between a junior employee and senior employees, and between a junior employee and workgroup peers affect the employee's likelihood of exiting in a given year overall, voluntarily, or as the result of being terminated. Below are the results of logit regression analyses from equation (1). Standard errors are in parentheses.

Relational Demography Predictors (Senior Match) Sex \% Match - Sr

Race \% Match - Sr

\section{Relational Demography Predictors (Peer Match)} Sex \% Match - Jr

Female x Sex \% Match - Jr

Race \% Match - Jr

UR Minority Race x Race \% Match - Jr

Senior/Peer Proportion Control

(\# of Seniors in gp)/(\# of Juniors in gp)

Individual Demography Controls

$$
\text { Part Time }
$$

Age

Female

UR Minority Race

Race Unknown

Years of Tenure Dummies

Context Controls ${ }^{1}$

Person-Period Observations

Number of Exit Events

Log likelihood

Likelihood-ratio $\mathrm{chi}^{2}$ (A nested in B)
Female x Sex \% Match - Sr

All Exits

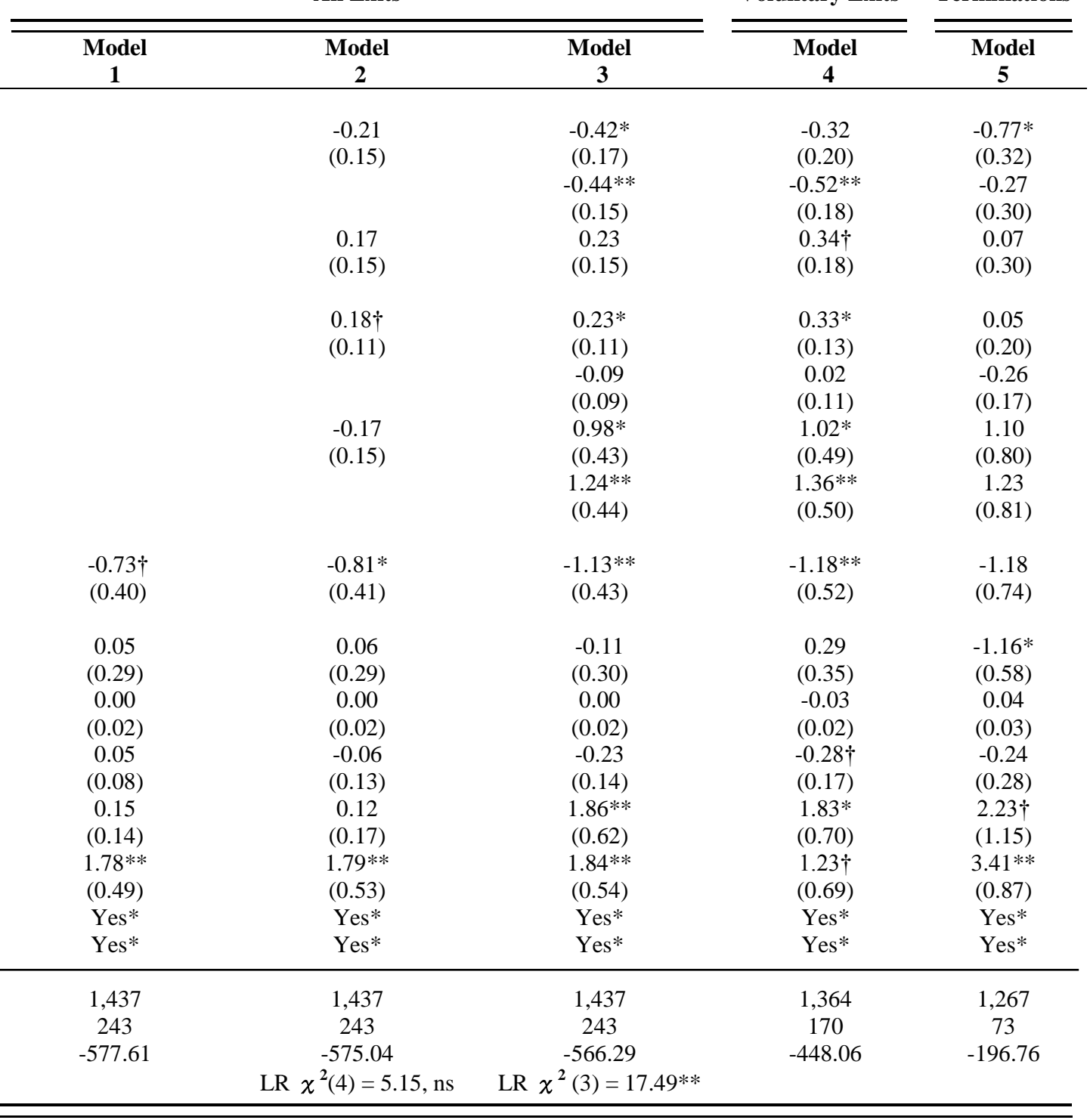

Significant at . 10, *Significant at .05, ${ }^{* *}$ Significant at .01 
${ }^{1}$ Context controls include year dummies, location dummies, department dummies, and workgroup too small dummies when match variables are included. 
Table 6. King's Rare Events Logit Regression is used to examine how the within-workgroup demographic similarities between a junior employee and senior employees, and between a junior employee and workgroup peers, affect the employee's likelihood of promotion over five years. Standard errors are in parentheses.

\begin{tabular}{|c|c|c|c|}
\hline & \multicolumn{3}{|c|}{ Promotions } \\
\hline & Model 6 & Model 7 & Model 8 \\
\hline \multicolumn{4}{|l|}{ Relational Demography Predictors (Senior Match) } \\
\hline \multirow[t]{2}{*}{ Avg. Sex \% Match - Sr } & & 0.47 & 0.61 \\
\hline & & $(0.46)$ & $(0.50)$ \\
\hline \multirow[t]{2}{*}{ Avg. Female x Avg. Sex \% Match - Sr } & & & $1.08 *$ \\
\hline & & & $(0.47)$ \\
\hline \multirow[t]{2}{*}{ Avg. Race \% Match - Sr } & & -0.52 & -0.46 \\
\hline & & $(1.11)$ & $(1.20)$ \\
\hline \multicolumn{4}{|l|}{ Relational Demography Predictors (Peer Match) } \\
\hline \multirow[t]{2}{*}{ Avg. Sex \% Match - Jr } & & 0.26 & 0.09 \\
\hline & & $(0.27)$ & $(0.32)$ \\
\hline \multirow[t]{2}{*}{ Female x Avg. Sex \% Match - Jr } & & & $-0.56 \dagger$ \\
\hline & & & $(0.31)$ \\
\hline \multirow[t]{2}{*}{ Avg. Race \% Match - Jr } & & $-0.84 *$ & $-1.08 * *$ \\
\hline & & $(0.40)$ & $(0.44)$ \\
\hline \multicolumn{4}{|l|}{ Senior/Peer Proportion Control } \\
\hline \multirow[t]{2}{*}{ Avg. (\# of Seniors in gp)/(\# of Juniors in gp) } & $1.73 *$ & $1.59 \dagger$ & $2.09 *$ \\
\hline & $(0.94)$ & $(0.89)$ & $(0.86)$ \\
\hline \multicolumn{4}{|l|}{ Individual Demography Controls } \\
\hline \multirow[t]{2}{*}{ Part Time } & -0.94 & -1.06 & -1.20 \\
\hline & $(1.16)$ & $(1.34)$ & $(1.37)$ \\
\hline \multirow[t]{2}{*}{ Age } & 0.03 & 0.02 & 0.03 \\
\hline & $(0.03)$ & $(0.03)$ & $(0.03)$ \\
\hline \multirow[t]{2}{*}{ Female } & $-0.41 \dagger$ & -0.01 & 0.01 \\
\hline & $(0.23)$ & $(0.47)$ & $(0.41)$ \\
\hline \multirow[t]{2}{*}{ Asian } & -0.20 & -2.60 & -2.92 \\
\hline & $(0.79)$ & $(2.40)$ & $(2.76)$ \\
\hline \multirow[t]{2}{*}{ Avg. Years of Tenure } & 0.15 & 0.19 & 0.22 \\
\hline & $(0.13)$ & $(0.13)$ & $(0.14)$ \\
\hline Context Controls ${ }^{1}$ & Yes & Yes & Yes \\
\hline Number of Observations & 396 & 396 & 396 \\
\hline
\end{tabular}

$\dagger$ Significant at .10, *Significant at .05, **Significant at .01

${ }^{1}$ Context controls include avg. year and office location dummies. 


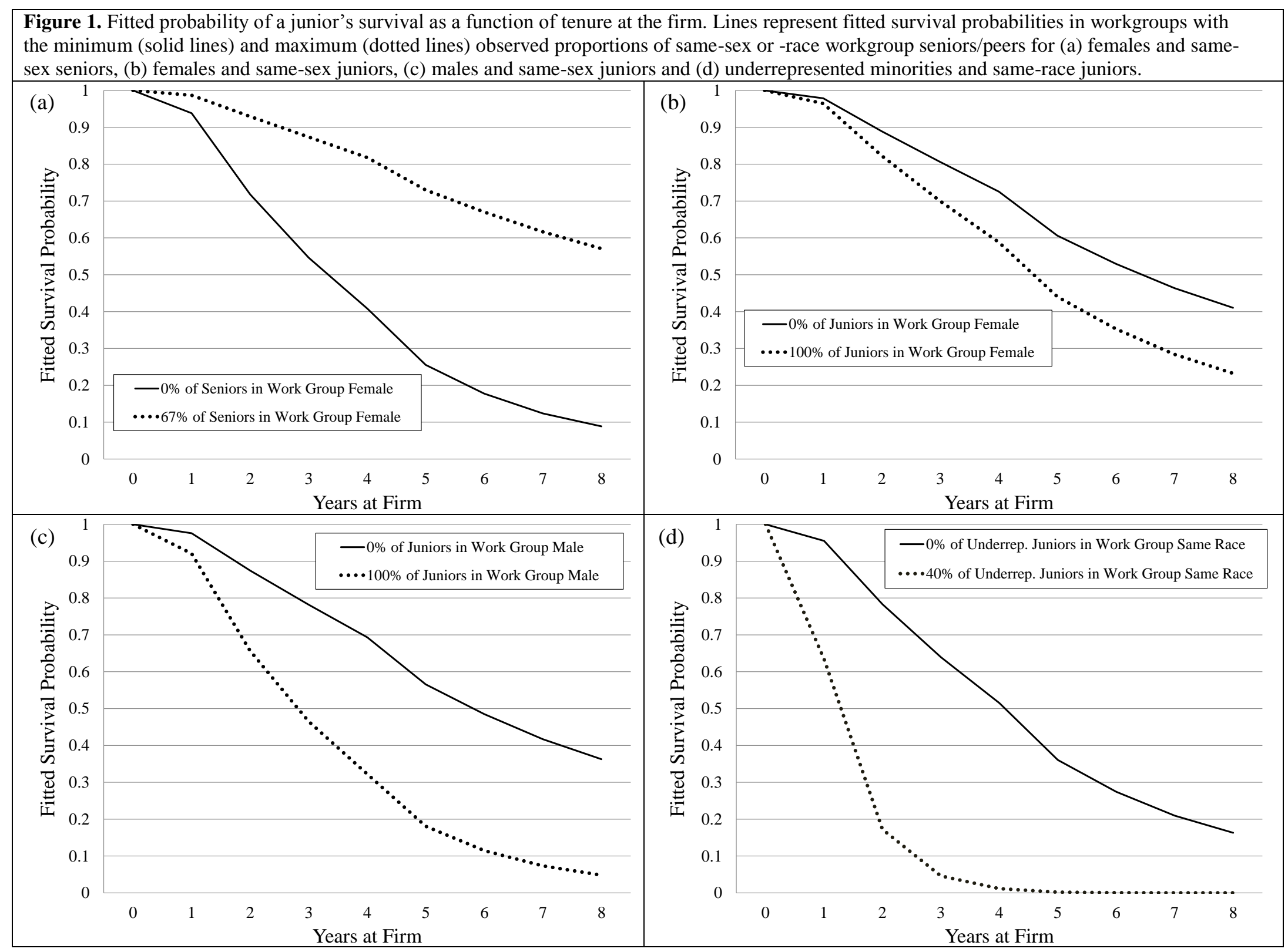




\section{References}

Aiken, L.S., S.G. West, R.R. Reno. 1991. Multiple regression: Testing and interpreting interactions. Sage Publications, Inc.

American Lawyer, T. 2010. Diversity Score Card 2010 The American Lawyer. ALM, American Lawyer.com.

Anderson-Gough, F., C. Grey, K. Robson. 2000. In the name of the client: The service ethic in two professional services firms. Human Relations 53(9) 1151-1174.

Baldi, S., D.B. McBrier. 1997. Do the Determinants of Promotion Differ for Blacks and Whites? Work and Occupations 24(4) 478-497.

Barker, P., K. Monks, F. Buckley. 1999. The Role of Mentoring in the Career Progression of Chartered Accountants. British Accounting Review 31 297-312.

Baron, J.N., M.T. Hannan, M.D. Burton. 2001. Labor Pains: Change in Organizational Models and Employee Turnover in Young, High-Tech Firms American Journal of Sociology 106(4) 960-1012.

Belliveau, M.A. 2005. Blind Ambition? The effects of social networks and institutional sex composition on the job search outcomes of elite coeducational and women's college graduates. Organization Science 16(2) $134-150$.

Berger, J., H.F. Fisek, R.Z. Norman, M.E. Zelditch. 1978. Status Characteristics and Social Interaction: An Expectation-States Approach. Elsevier, New York.

Bertrand, M., C. Goldin, L.F. Katz. 2009. Dynamics of the Gender Gap for Young Professionals in the Financial and Corporate Sectors NBER Working Papers.

Blalock, H.M. 1967. Toward a theory of minority-group relations. Wiley, New York.

Bobo, L., V.L. Hutchings. 1996. Perceptions of Racial Group Competition: Extending Blumer's Theory of Group Position to a Multiracial Social Context. American Sociological Review 61(6) 951-972.

Brass, D.J. 1984. Being in the right place: A structural analysis if Individual Influence in an organization. Administrative Science Quarterly 29(4) 518-539.

Brewer, M.B., J.G. Weber. 1994. Self-evaluation effects of interpersonal versus intergroup social comparison. Journal of Personality and Social Psychology 66(2) 268-275.

Byrne, D.E. 1971. The attraction paradigm. Academic Press, New York.

Castilla, E.J. 2011. Bringing Managers Back In. American Sociological Review 76(5) 667-694.

Castilla, E.J., S. Benard. 2010. The Paradox of Meritocracy in Organizations. Administrative Science Quarterly 55(4) 543-576.

Chattopadhyay, P., E. George, A.D. Shulman. 2008. The Asymmetrical Influence of Sex Dissimilarity in Distributive vs Colocated Work Groups. Organization Science 19(4) 581-593. 
Cohen, L.E., J.P. Broschak, H.A. Haveman. 1998. And Then There Were More? The Effect of Organizational Sex Composition on the Hiring and Promotion of Managers. American Sociological Review 63(5) 711-727.

Collins, J. 2009. Law Firm Diversity Demographics Show Little Change, Despite Economic Downturn: Representation in Some Markets Declines While Others Show Small Gains NALP: The Association for Legal Career Professionals.

Cota, A.A., K.L. Dion. 1986. Salience of gender and sex composition of ad hoc groups: An experimental test of distinctiveness theory. Journal of Personality and Social Psychology 50(4) 770-776.

Duguid, M.M., D.L. Loyd, P.S. Tolbert. 2010. The Impact of Categorical Status, Numeric Representation, and Work Group Prestige on Preference for Demographically Similar Others: A Value Threat Approach. Organization Science Articles in Advance 1-16.

Eagly, A.H., L.L. Carli. 2007. Through the Labyrinth: The Truth About How Women Become Leaders. Harvard Business School Press, Boston, MA.

Elliott, J.R., R.A. Smith. 2004. Race, Gender, and Workplace Power. American Sociological Review 69(3) 319-344.

Elvira, M.M., L.E. Cohen. 2001. Location matters: A cross-level analysis of the effects of organizational sex composition on turnover. Academy of Management Journal 44(3) 591-605.

Fernandez, R.M., I. Fernandez-Mateo. 2006. Networks, Race, and Hiring. American Sociological Review 71(1) 42-71.

Frable, D.E.S. 1997. Gender, racial, ethnic, sexual, and class identities. Annual Review of Psychology 48(1) 139 - 162.

Gandz, J., V.V. Murray. 1980. The experience of workplace politics. Academy of Management Journal 237-251.

Gorman, E.H. 2006. Work Uncertainty and the Promotion of Professional Women: The Case of Law Firm Partnership. Social Forces 85(2) 865-890.

Harrison, D.A., K.J. Klein. 2007. What's the difference? Diversity constructs as separation, variety, or disparity in organizations. Academy of Management Review 32(4) 1199-1228.

Hewlett, S.A., C.B. Luce. 2006. Extreme jobs-The dangerous allure of the 70-hour workweek. Harvard Business Review 84(12) 49-59.

Hogg, M.A., D.J. Terry. 2000. Social Identity and Self-Categorization Processes in Organizational Contexts. Academy of Management Review 25(1) 121-140.

Hom, P.W., L. Roberson, A.D. Ellis. 2008. Challenging Conventional Wisdom About Who Quits: Revelations From Corporate America. Journal of Applied Psychology 93(1) 1-34.

Hull, K.E., R.L. Nelson. 2000. Assimilation, Choice, or Constraint? Testing Theories of Gender Differences in the Careers of Lawyers. Social Forces 79(1) 229-264. 
Ibarra, H. 1992. Homophily and differential returns: Sex differences in network structure and access in an advertising firm. Administrative Science Quarterly 37(3) 422-447.

Ibarra, H. 1995. Race, opportunity, and diversity of social circles in managerial networks. Academy of Management Journal 38(3) 673-703.

Jackson, S.E., J.F. Brett, V.I. Sessa, D.M. Cooper, J.A. Julin, K. Peyronnin. 1991. Some differences make a difference: Individual dissimilarity and group heterogeneity as correlates of recruitment, promotions, and turnover. Journal of Applied Psychology 76(5) 675-689.

Kahn, C., G. Huberman. 1988. Two-sided uncertainty and" up-or-out" contracts. Journal of Labor Economics 6(4) 423-444.

Kanter, R.M. 1977a. Men and Women of the Corporation. Basic Books, New York.

Kanter, R.M. 1977b. Some effects of proportions on group life: Skewed sex ratios and responses to token women. American Journal of Sociology 82(5) 965-990.

Kay, F.M., J. Hagan. 1998. Raising the bar: The gender stratification of law-firm capital. American Sociological Review 63(5) 728-743.

Kilduff, G.J., H.A. Elfenbein, B.M. Staw. 2010. The Psychology of Rivalry: A Relationally-dependent Analysis of Competition. Academy of Management Journal 53(5) 943-969.

King, G., L. Zeng. 2001. Logistic regression in rare events data. Political analysis 9(2) 137-163.

Krackhardt, D., L.W. Porter. 1986. The snowball effect: Turnover embedded in communication networks. Journal of Applied Psychology 71(1) 50-55.

Kruglanski, A.W., O. Mayseless. 1990. Classic and current social comparison research: Expanding the perspective. Psychological Bulletin 108(2) 195-208.

Lehmann, J.Y. 2011. Job assignment and promotion under statistical discrimination: evidence from the early careers of lawyers mpra.ub.uni-muenchen.de. University of Muenchen, Germany.

Leonard, J.S., D.I. Levine. 2006. Effect of Diversity on Turnover: A Large Case Study, The. Industrial \& Labor Relations Review 59(4) 547-572.

Lincoln, J.R., J. Miller. 1979. Work and friendship ties in organizations: A comparative analysis of relational networks. Administrative Science Quarterly 24(2) 181-199.

Major, B., B. Forcey. 1985. Social comparisons and pay evaluations: Preferences for same-sex and samejob wage comparisons. Journal of Experimental Social Psychology 21(4) 393-405.

Major, B., D.B. McFarlin, D. Gagnon. 1984. Overworked and underpaid: On the nature of gender differences in personal entitlement. Journal of Personality and Social Psychology 47(6) 1399-1412.

Maume, D.J. 1999. Glass Ceilings and Glass Escalators. Work and Occupations 26(4) 483-509.

Mehra, A., M. Kilduff, D.J. Brass. 1998. At the margins: A distinctiveness approach to the social identity and social networks of underrepresented groups. Academy of Management Journal 41(4) 441-452. 
Morita, J.G., T.W. Lee, R.T. Mowday. 1993. The Regression-Analog to Survival Analysis: A Selected Application to Turnover Research. The Academy of Management Journal 36(6) 1430-1464.

Mussweiler, T. 2003. Comparison processes in social judgment: Mechanisms and consequences. Psychological Review 110(3) 472-488.

O'Reilly, C.A., D.F. Caldwell, W.P. Barnett. 1989. Work group demography, social integration, and turnover. Administrative Science Quarterly 34(1) 21-37.

Popielarz, P.A., J.M. McPherson. 1995. On the Edge or In Between: Niche Position, Niche Overlap, and the Duration of Voluntary Association Memberships. American Journal of Sociology 101(3) 698-720.

Porter, J.R., R.E. Washington. 1993. Minority Identity and Self-Esteem. Annual Review of Sociology 19 139-161.

Ragins, B.R., D.B. McFarlin. 1990. Perceptions of mentor roles in cross-gender mentoring relationships. Journal of Vocational Behavior 37 321-339.

Reagans, R. 2005. Preferences, identity, and competition: Predicting tie strength from demographic data. Management Science 51(9) 1374-1383.

Riordan, C.M., L.M. Shore. 1997. Demographic Diversity and Employee Attitudes: An Empirical Examination of Relational Demography Within Work Units. Journal of Applied Psychology 82(3) 342358.

Roberson, L., B.M. Galvin, A.C. Charles. 2007. When Group Identities Matter: Bias in Performance Appraisal. The Academy of Management Annals 1(1) 617 - 650.

Roth, L.M. 2003. Selling women short: A research note on gender differences in compensation on Wall Street. Social Forces 82(2) 783-802.

Scandura, T.A. 1992. Mentorship and career mobility: An empirical investigation. Journal of Organizational Behavior 13(2) 169 - 174.

Sherer, P.D. 1994. Leveraging human assets in law firms: Human capital structures and organizational capabilities. Indusrial \& Labor Relations Review 48(4) 671-691.

Singer, J.D., J.B. Willett. 1993. It's About Time: Using Discrete-Time Survival Analysis to Study Duration and the Timing of Events. Journal of Educational and Behavioral Statistics 18(2) 155-195.

Smith, R.A. 2002. Race, gender, and authority in the workplace: Theory and Research. Annual Review of Sociology 28(1) 509-542.

Sørensen, J.B. 2000. The Longitudinal Effects of Group Tenure Composition on Turnover. American Sociological Review 65(2) 298-310.

Sørensen, Jesper B. 2004. The Organizational Demography of Racial Employment Segregation. American Journal of Sociology 110(3) 626-671.

South, S.J., C.M. Bonjean, J. Corder, W.T. Markham. 1982a. Sex and power in the federal bureaucracy: a comparative analysis of male and female supervisors. Work and Occupations 9(2) 233. 
South, S.J., C.M. Bonjean, W.T. Markham, J. Corder. 1982b. Social Structure and Intergroup Interaction: Men and Women of the Federal Bureaucracy American Sociological Review 47(5) 587-599.

Tajfel, H. 1974. Social identity and intergroup behaviour. Social science information 13(2) 65-93.

Tajfel, H., J.C. Turner. 1986. The social identity theory of intergroup behavior. S. Worchel, L.W. Austin, eds. Psychology of intergroup relations. Nelson-Hall, Chicago, 7-24.

Tolbert, P.S., T. Simons, A. Andrews, J. Rhee. 1995. The effects of gender composition in academic departments on faculty turnover. Industrial and Labor Relations Review 48(3) 562-579.

Tsui, A.S., B.A. Gutek. 1999. Demographic Differences in Organizations: Current Research and Future Directions. Lexington Books, New York.

Tsui, A.S., C.A. O'Reilly. 1989. Beyond Simple Demographic Effects: The Importance of Relational Demography in Superior-Subordinate Dyads. Academy of Management Journal 32(2) 402-423.

Tsui, A.S., L. Porter, T. Egan. 2002. When both similarities and dissimilarities matter: Extending the concept of relational demography. Human Relations 55(8) 899-929.

Von Nordenflycht, A. 2010. What is a Professional Service Firm? Toward a Theory and Taxonomy of Knowledge-Intensive Firms. Academy of Management Review 35(1) 155 - 174

Williams, K.Y., C.A. O'Reilly. 1998. Demography and diversity in organizations: A review of 40 years of research. B.M. Staw, L.L. Cummings, eds. Research in Organizational Behavior. JAI Press, Greenwich, CN, 77-140.

Zatzick, C.D., M.M. Elvira, L.E. Cohen. 2003. When is More Better? The Effects of Racial Composition on Voluntary Turnover. Organization Science 14(5) 483-496. 